\title{
POLYCHLORINATED BIPHENYLS IN HUMAN BLOOD
}

\author{
YOSHITO INOUE, SUMIKO ABE, HIROJI ESAKI, \\ AND MAKOTO TAKAMATSU \\ Department of Environmental Health, Kurume University \\ School of Medicine, Kurume, Japan
}

(Received for publication June 25, 1973)

\begin{abstract}
PCB was detected in all samples of blood plasma. The plasma PCB levels of normal persons ranged from $1 \mathrm{ppb}$ to $7 \mathrm{ppb}$, and that of the patients ranged widely from $2 \mathrm{ppb}$ to $15 \mathrm{ppb}$, the latter were higher than the former statistically $(\mathrm{P}<0.05)$. $\mathrm{PCB}$ of patients' plasma showed very characteristic gas chromatograms both in quality and quantity. The urban residents had more $\mathrm{PCB}$ in their blood than the rural $(\mathrm{P}<0.01)$.
\end{abstract}

In the spring of 1968 , several hundreds of thousands of chickens died suddenly in western Japan. Soon in the same area a great many persons were found to suffer from illness manifested mainly by acne-like skin eruption. In further investigation, it revealed that they had been taking Kanemi Rice Oil, a common food stuffs manifactured by Kanemi Rice Oil Co. Ltd., for several months until they got ill. And according to an analytical study, polychlorinated hiphenyls (PCB) was found in the oil ${ }^{8)}$. PCB was used as a heat transfer agent in one of the processes of purifying the rice oil and contained mainly tetra-chlorobiphenyls. Later the disease was named "Kanemi Yusho" (PCB poisoning), and the strange death of chickens was also found to be caused by taking feed stuffs added the byproduct of Kanemi Rice Oil.

Five years later, because no satisfactory therapy has been introduced, about 10,000 patients are still suffering from "Kanemi Yusho".

PCB has been used industrially since 1929 and has been spread gradually into the natural environment. However the accumulation of PCB in nature was not detected until 19695). Recently PCB was found in human milk $^{1}$, adipose tissue $^{1 / 2)}$ and blood plasma ${ }^{5)}$.

The purpose of the present study is to investigate the degree of contamination of human by PCB by assaying its concentration in the plasma of normal persons and patients of PCB poisoning.

\section{MATERIALS AND METHODS}

Samples : Plasma samples were obtained from 44 normal persons and 11 patients of PCB poisoning in western Japan from August of 1972 to February of 1973. Among the normal persons, 15 were from three cities and 26 were from two farming villages. About $10 \mathrm{ml}$ of blood was drawn from each person. The plasma was separated and kept frozen until the time of assaying.

Analysis : The extraction and cleanup of the plasma were performed basically according to the method of Jensen ${ }^{6}$ ) 
with several modifications.

In a test tube containing $4 \mathrm{ml}$ plasma to which $3 \mathrm{ml}$ acetonitrile, $1 \mathrm{ml}$ formic acid and $4 \mathrm{ml}$ hexane were added. The tube was shaking for 30 minutes and centrifuged for 10 minutes at 4,000 rpm. The upper layer was pipeted to another test tube, and the lower layer was extracted with hexane once more. Then an equal volume fuming sulphuric acid ( $7 \%$ sulphur trioxide) was added to the tube containing the hexane extract. The tube was turned up and down about 10 times (no shaking). After centrifugation, the hexane extract was concentrated and the contaminants were further removed by passing through a silica column containing $2 \mathrm{~g}$ of silica gel of $\mathrm{Merck}^{4)}$ activated at $120^{\circ} \mathrm{C}$ for 2 hours and partially deactivated with $5 \%$ by weight of water. PCB was eluted in the first $5 \mathrm{ml}$ of hexane. The hexane eluate was concentrated and then injected into the gas chrmatograph.

A Shimazu GC-5APFE ( $\left.{ }^{3} \mathrm{H}-\mathrm{ECD}\right)$ gas chromatogram was used. The column consisted of SE-30 (1.5\%) or QF-1 (2.0\%) on 60-80 mesh silanized acid washed chromosorb W. The column temperature was $195^{\circ} \mathrm{C}$ and the detector temperature was $210^{\circ} \mathrm{C}$.

\section{RESULTS}

Table 1 showed the concentrations of PCB in the blood of normal persons and the patients. PCB was present at detectable level in all plasma of the studied groups. The plasma PCB levels of normal persons ranged from $1 \mathrm{ppb}$ to $7 \mathrm{ppb}$, and averaged $3.3 \pm 1.3 \mathrm{ppb}$. The plasma PCB levels of the urban residents were higher than that of the rural residents $(\mathrm{P}<0.01)$ (table-2).

On the other hand, the plasma PCB levels of the patients ranged from $2 \mathrm{ppb}$ to $15 \mathrm{ppb}$, and averaged $7.0 \pm 4.1 \mathrm{ppb}$. Though the range was wide, the pati- ents' plasma contained higher levels of PCB than that of the normal significantly $(\mathrm{P}<0.05)$.

TABLE 1

PCB levels in human plasma (ppb)

\begin{tabular}{crrc} 
Group & No. & Range & Mean \\
\hline Normal & 44 & $1-7$ & $3.3 \pm 1.3$ \\
Patients & 11 & $2-15$ & $7.0 \pm 4.1$ \\
\hline \multicolumn{4}{c}{$\mathrm{P}<0.05$}
\end{tabular}

TABLB 2

Comparison of PCB levels (ppb)

\begin{tabular}{cccc} 
Group & No. & Range & Mean \\
\hline Urban & 13 & $2-7$ & $4.5 \pm 1.4$ \\
Rural & 29 & $1-5$ & $2.7 \pm 0.9$ \\
\hline \multicolumn{4}{c}{$\mathrm{P}<0.01$}
\end{tabular}

Gas chromatographic patterns of PCB in normal persons' plasma (figure-1-D) were similar to that of Kanechlor-500 (mixed chlorinated biphenyls) (figure1-E), but the patterns of nearly all the patients showed to decrease at peak 13 and increase at peak 17 (figure-1-C). It was so characteristic that we might say the PCB in patients' plasma showed quite different gas chromatograms from that of normal persons not only in quality but also in quantity.

\section{DISCUSSION}

Considerable high levels of PCB have been found to contain in fishes. So it is thought that the more fish people take, the more PCB will accumulate in their bodies. The main reason of the urban residents having higher $\mathrm{PCB}$ levels than the rural is probably due to their different dietary life, in general, the urban eat more fish than the rural. However the difference may be due to not only the PCB contaminated fish but 


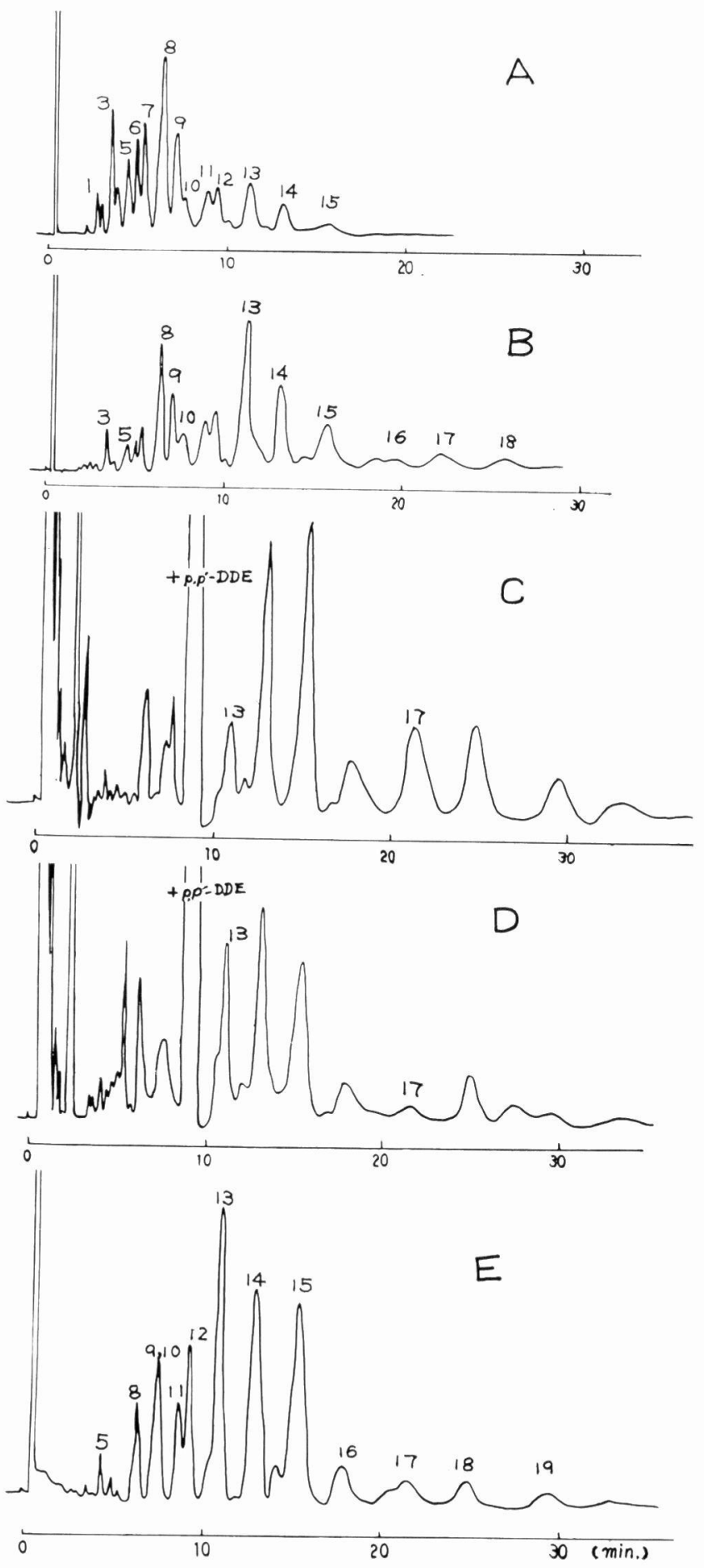

Figure 1 Five gas chromatograms

(A) A technical sample of Kanechlor- 400 .

(B) An extract of the rice oil contaminated with Kanechlor400.

(C) An extract of blood plasma from a PCB patient.

(D) An extract of blood from a normal person.

(E) A technical sample of Kanechlor-500. 
also the contaminated water and air.

There is a statistical difference between the patients and normal persons in blood PCB levels, however, a few of the patients' blood plasma contained as low levels of PCB as normal persons. Almost all the PCB gas chromatograms of the patients differed apparently from that of normal persons.

Hasegawa et al. ${ }^{3}$ found the plasma of worker who had treated PCB before contained mainly low chlorinated PCB. Tsukamoto et al. ${ }^{7}$ and Yoshimura et al. ${ }^{8)}$ reported that low chlorinated PCB was excreted rapidly and mainly high chlorinated PCB residued in the bodies of rabbits ${ }^{7)}$ and mice ${ }^{8)}$ having administered PCB orally. Tsukamoto et al. ${ }^{7}$ also reported that high chlorinated $\mathrm{PCB}$ residued in the patients of $\mathrm{PCB}$ poisoning.

Our investigation showed that mainly high chlorinated PCB existed in the blood plasma of both the patients and normal persons.

Furthermore, we recognized peculiar accumulation of PCB in the blood plasma of PCB poisoned patients from the gas chromatograms which showed very high peak 17 and very low peak 13 as compared to that of normal persons, though it is not sure whether this is due to abnormal metabolism caused by sub-acute intoxication or not. In order to make sure how PCB acts on human body, we think a survey of blood PCB of normal persons only is not enough, a more thorough follow-up study on PCB patients and the workers having treated PCB should also be performed.

\section{ACKNOWLEDGMENT}

The authors thank Dr. K. Fujiwara and his coworkers of Kyoto City Institute of Hygiene for their advice and guidance of this work.

\section{REFERENCES}

1) Acker, L. and Schulte, E. : Occurence of chlorinated biphenyls and hexachlorobenzene together with chlorinated insecticides in human milk and adipose tissue. Naturwissenschaften $\mathbf{5 7}, \mathbf{4 9 7}, 1970$.

2 ) Biros, F. J. and Walker, A. C. : Polychlorinated biphenyls in human adipose tissue. Bull. Environm. Contam. and Toxicol. 5, 317, 1970.

3 ) HASEGAW , H. et al. : Jap. J. Ind. Health (in the press) (in Japanese).

4) Holden, A. V. and MARSDen, K. : Singlestage clean-up of animal tissue extracts for organochlorine residue analysis. J. Chromatog. 44, 481, 1969.

5) JENSEn, S. : The PCB story. Ambio 1, 123. 1972.

6 ) JENSEN, S. : (A private letter).

7 ) Tsukamoto, H. et al. : The chemical studies on detection of toxic compounds in the rice oils used by the patients of Yusho. Fukuoka Acta Medica. 60, 496, 1969 (in Japanese).

8) Yoshimura, H. and Oshima, M. : Studies on the tissue distribution and elimination of several components of KC-400 (chlorobiphenyls) in mice. Fukuoka Acta Medica. 62, 5, 1971 (in Japanese). 